\title{
Burnout syndrome, associated factors and coping strategies of Jaffna Medical Students
}

\author{
${ }^{1}$ Weerasinghe RHM, 'Lakmali JMD, ${ }^{1}$ De Silva BHKG, ${ }^{1}$ Ramya Kumar, 'Sathiadas MG \\ ${ }^{1}$ Faculty of Medicine, University of Jaffna
}

\begin{abstract}
Introduction and objectives: Burnout syndrome (BOS) is seen amongst Medical students which leads to chronic stress and need coping mechanisms to overcome it. This study aims to determine the prevalence of BOS, associated factors and coping strategies adopted by students of the Faculty of Medicine, Jaffna.
\end{abstract}

Methodology: This descriptive cross sectional institutional based study was carried out among first to fourth year medical students. Data were collected using a self-administered questionnaire. BOS was measured using the Oldenburg Burnout Inventory (Student version)1. Data was entered and analysed using SPSS version 26. Chi Squared was used to assess the associated factors. Ethical clearance was obtained from the Faculty of Medicine, Jaffna.

Results: A total of 561 were considered and the response rate was $81 \%(455)$. Male Female ratio was $1: 1.5$. BOS was seen in $381(83.7 \%)$, $86.3 \%$ were females, $88.5 \%$ were Sinhalese and $88.8 \%$ lived in hostels. A total of $104(86.0 \%)$ had English difficulties, $85 \%$ (239) felt homesick, $84.3 \%$ spent $<2$ hours in leisure activities and $86.6 \%$ missed main meals. BOS was significantly associated with year of study $(\mathrm{p}=0.048)$, performance at examination $(p=0.019)$, Use of social media $(\mathrm{p}=0.021)$, dietary habits $(\mathrm{p}=0.027)$ and interaction with teachers $(\mathrm{p}=0.032)$. The coping strategies were being positive $(88.1 \%)$, getting advice $(75.6 \%)$, listening to music $(77 \%)$, finding comfort in religious activities(77.4\%) and getting emotional support(77.9\%). Keeping feelings to one's self and solving problems alone $(54.5 \%)$ were commonly reported avoidant strategies.

Conclusion: BOS among medical students is seen and some groups are more vulnerable. Year of study, performance at examination, dietary habits, use of social media and interaction with teachers contributed to the BOS.

\section{Keywords}

Burnout syndrome, coping strategies, medical students, Jaffna

\section{Introduction}

Burnout syndrome (BOS) is characterized by exhaustion, disengagement, and reduced work performance (1) BOS has detrimental effects on healthcare workers and patients. Burnt out healthcare workers may demonstrate errors of judgment, resulting in adverse patient outcomes (2)

Number of studies on BOS have been carried out on medical students in Sri Lanka. Research from India, China and Brazil reveal BOS prevalence rates ranging from 10 to 52 per cent among medical students(3,4\&5). Male gender, younger age, rural residence, senior year of study, advanced semester, medium of instruction, enrollment in a higher number of courses, attending complementary courses, dissatisfaction with the course, intention to drop out of the course, lack of professional experience, lack of leisure time, less support from family, friends and organizations, poor interpersonal relationships, and mental illness, are known to be predictors of BOS $(4,5 \& 6)$.

Various strategies are adopted to cope with BOS. Defined as specific efforts, both behavioral and psychological, employed to master, tolerate, reduce or minimize stressful events (7), coping strategies can be active (problem-focused) or avoidant (emotion-focused). Active coping involves identifying problems and finding solutions, whereas avoidant coping focuses on reducing, regulating or removing sources of stress $(8,9)$.

Corresponding author: Sathiadas MG, email: docsathiadas@hotmail.com, iD https://orcid.org/0000-0002-7822-0447, Submitted: January 2020 Accepted June 2020

This is an open-access article distributed under the terms of the Creative Commons Attribution 4.0 International License, which permits unrestricted use, distribution and reproduction in any medium provided the original author and source are credited 
The Faculty of Medicine, University of Jaffna, is one of eleven medical faculties in the state university system, producing over a 100 doctors per year. With a tight schedule and few breaks during the five-year undergraduate medical programme, medical students in Sri Lanka are vulnerable to chronic stress. A study among Jaffna University students revealed high stress levels(10). This study determines the prevalence and associated factors of BOS and the coping strategies adopted by the medical students of University of Jaffna.

\section{Methods}

This descriptive cross-sectional institutional-based study was carried out between May 2018 and May 2019 amongst first to fourth year medical students registered at the University of Jaffna. Sample size was calculated using $n=(z 2 \times p \times(100-p)) / d 2$ with $10 \%$ for non-response; the calculated sample size was 427 . We included all 561 students that comprised our study population.

A self-administered questionnaire consisting of three sections was used to collect data. The first section was designed to obtain data on sociodemographic, academic and lifestyle factors. The second section contained the internationally validated Oldenburg Burnout Inventory-Student Version (OLBI-S), which is available free-ofcharge for non-commercial use. The third section included questions on coping strategies used by students.

The OLBI-S comprises 16 questions; 8 questions on exhaustion and 8 questions on disengagement. The two sets of questions are scored separately, and the mean value of exhaustion and disengagement is considered against a cut off value of 2.25 for emotional exhaustion and 2.1 for disengagement. Scoring above the cutoffs for both emotional exhaustion and disengagement is conclusive of the presence of burnout (11).

Data were collected by the investigators in the evenings when the students were free with the necessary administrative approvals. Prospective participants were informed about the purpose and procedures of the study. Willing participants were given the self-administered questionnaire, which was completed in the presence of the data collector. The filled questionnaires were collected in a ballot box.
Data were entered and analyzed with the help of the Statistical Package for Social Sciences (SPSS v26). Frequencies and proportions were used to describe BOS and other variables. The Chi Squared test was used to assess the association between BOS and sociodemographic, academic, and lifestyle factors. Alpha was set at 0.05 .

Ethics approval was obtained from the Ethics Review Committee of the Faculty of Medicine, University of Jaffna.

\section{Results}

In total, 455 first to fourth year students participated with a response rate of $81.1 \%$. The sample was made up of $185(40.7 \%)$ males and $270(59.3 \%)$ females. Amongst them 232 (51.0\%) were Sri Lankan Tamil, 148 (32.5\%) Sinhala, 68 (14.9\%) Muslim, and 7 (1.5\%) Indian Tamil (Table 1).

Table 1. Demographic profile of participants $(\mathrm{n}=455)$

\begin{tabular}{|c|c|c|}
\hline & Frequency & Percentage \\
\hline \multicolumn{3}{|l|}{ Gender } \\
\hline Female & 270 & 59.3 \\
\hline Male & 185 & 40.7 \\
\hline \multicolumn{3}{|l|}{ Ethnicity } \\
\hline Sri Lankan Tamil & 232 & 51.0 \\
\hline Sinhala & 148 & 32.5 \\
\hline Muslim & 68 & 14.9 \\
\hline Indian Tamil & 7 & 1.5 \\
\hline
\end{tabular}

In the sample, a total of $381(83.7 \%)$ participants recorded scores on the Oldenburg Burnout Inventory that were consistent with burnout (Figure $1)$.

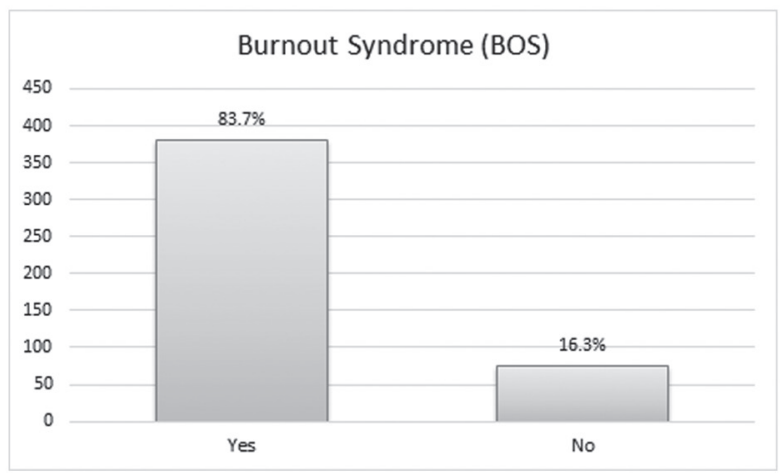

Figure 1. Prevalence of burnout syndrome 
A total of 381 (83.7\%) participants recorded scores consistent with burnout (Figure 1). There was a significant association between the presence of burnout and year of study ( $\mathrm{p}=0.048)$ where first and second students were more affected than other years of study. There was no evidence of an association between the presence of burnout and sex, ethnicity, experiencing financial difficulties or type of residence in Jaffna (Table 2).

Table 2. Sociodemographic factors associated with burnout syndrome $(n=455)$

\begin{tabular}{|c|c|c|c|c|c|}
\hline \multirow{3}{*}{$\begin{array}{l}\text { Sociode- } \\
\text { mographic } \\
\text { Factors }\end{array}$} & \multicolumn{4}{|c|}{ Burnout } & \\
\hline & \multicolumn{2}{|c|}{ Yes } & \multicolumn{2}{|c|}{ No } & \\
\hline & $\mathrm{n}$ & $\%$ & $\mathrm{n}$ & $\%$ & $\begin{array}{c}\text { Chi } \\
\text { square test }\end{array}$ \\
\hline \multicolumn{5}{|l|}{ Sex } & \multirow{3}{*}{$\begin{array}{l}x^{2}=3.196 \\
p=0.074\end{array}$} \\
\hline Male & 148 & 80 & 37 & 20 & \\
\hline Female & 233 & 86.3 & 37 & 13.7 & \\
\hline \multicolumn{5}{|l|}{ Ethnicity } & \multirow{5}{*}{$\begin{array}{l}x^{2}=5.946 \\
p=0.114\end{array}$} \\
\hline Sinhala & 131 & 88.5 & 17 & 11.5 & \\
\hline Muslim & 52 & 76.5 & 16 & 23.5 & \\
\hline $\begin{array}{l}\text { Sri Lankan } \\
\text { Tamil }\end{array}$ & 193 & 83.2 & 39 & 16.8 & \\
\hline Indian Tamil & 5 & 71.4 & 2 & 28.6 & \\
\hline \multicolumn{5}{|l|}{ Year of study } & \multirow{5}{*}{$\begin{array}{l}x^{2}=7.915 \\
p=0.048^{*}\end{array}$} \\
\hline $\begin{array}{l}4^{\text {th }} \text { Year }\left(37^{\text {th }}\right. \\
\text { Batch })\end{array}$ & 90 & 84.9 & 16 & 15.1 & \\
\hline $\begin{array}{l}3^{\text {rd }} \text { Year }\left(38^{\text {th }}\right. \\
\text { Batch })\end{array}$ & 79 & 76.7 & 24 & 23.3 & \\
\hline $\begin{array}{l}2^{\text {nd }} \text { Year }\left(39^{\text {th }}\right. \\
\text { Batch })\end{array}$ & 111 & 90.2 & 12 & 9.8 & \\
\hline $\begin{array}{l}1^{\text {st }} \text { Year }\left(40^{\text {th }}\right. \\
\text { Batch) }\end{array}$ & 101 & 82 & 22 & 17.9 & \\
\hline \multicolumn{5}{|c|}{ Financial Difficulties } & $\mathrm{x}^{2}=4.297$ \\
\hline Yes & 211 & 87.2 & 31 & 12.8 & \multirow{2}{*}{$p=0.380$} \\
\hline No & 159 & 79.9 & 40 & 20.1 & \\
\hline \multicolumn{5}{|l|}{ Residence } & \multirow{5}{*}{$\begin{array}{l}x^{2}=6.521 \\
p=0.089\end{array}$} \\
\hline Home & 75 & 80.6 & 18 & 19.4 & \\
\hline Boarding & 137 & 80.1 & 34 & 19.9 & \\
\hline Hostel & 167 & 88.8 & 21 & 11.2 & \\
\hline Others & 2 & 66.7 & 1 & 33.3 & \\
\hline
\end{tabular}

With respect to academic factors, BOS was significantly associated with poor performance at the First Examination for Medical Degrees $(p=0.019)$ and fewer interactions with lecturers $(p=0.021)$. Social media use for $>2$ hours per day $(p=0.021)$ and changed dietary habits $(p=0.027)$ were lifestyle factors that were significantly associated with burnout. Here, common dietary changes reported by students included missing main meals $(86.6 \%)$, eating more fast food $(85.5 \%)$, reduced intake of fruits and vegetables $(85.1 \%)$. Language difficulties, time spent on leisure activities and feeling homesick were not associated with BOS at the 0.05 level.

Table 3. Academic and lifestyle factors associated with burnout syndrome

\begin{tabular}{|c|c|c|c|c|c|}
\hline \multirow{3}{*}{$\begin{array}{c}\text { Academic } \\
\& \text { Lifestyle } \\
\text { Factors }\end{array}$} & \multicolumn{4}{|c|}{ Burnout } & \\
\hline & \multicolumn{2}{|l|}{ Yes } & \multicolumn{2}{|l|}{ No } & \\
\hline & $\mathrm{n}$ & $\%$ & $\mathrm{n}$ & $\%$ & $\begin{array}{l}\text { Chi square } \\
\text { test }\end{array}$ \\
\hline \multicolumn{5}{|c|}{$1^{\text {st }}$ Examination $(\mathrm{n}=179)^{*}$} & \multirow{4}{*}{$\begin{array}{l}\mathrm{x}^{2}=7.9 \\
\mathrm{p}=0.019^{*}\end{array}$} \\
\hline Proper Pass & 93 & 76.9 & 28 & 23.1 & \\
\hline Repeat & 75 & 88.2 & 10 & 11.8 & \\
\hline Batch Miss & 11 & 100 & 0 & 0 & \\
\hline \multicolumn{5}{|c|}{ Language Difficulty $(\mathrm{n}=234)^{*}$} & \multirow{4}{*}{$\begin{array}{l}x^{2=} 0.189 \\
p=0.910\end{array}$} \\
\hline English & 104 & 86.0 & 17 & 14.0 & \\
\hline Tamil & 60 & 85.7 & 10 & 14.3 & \\
\hline Both & 38 & 88.4 & 5 & 11.6 & \\
\hline \multicolumn{5}{|c|}{ Interaction with Lecturers $(\mathrm{n}=432)$} & \multirow{4}{*}{$\begin{array}{l}x^{2}=9.314 \\
p=0.009 *\end{array}$} \\
\hline Frequently & 74 & 74.0 & 26 & 26.0 & \\
\hline Occasionally & 133 & 87.5 & 19 & 12.5 & \\
\hline Rarely & 155 & 86.1 & 25 & 13.9 & \\
\hline \multicolumn{5}{|c|}{ Social Media $(n=434)$} & \multirow{3}{*}{$\begin{array}{l}\mathrm{x}^{2}=5.303 \\
\mathrm{p}=0.021 *\end{array}$} \\
\hline$<2$ hours /day & 143 & 78.6 & 39 & 21.4 & \\
\hline $\begin{array}{l}>=2 \text { hours a } \\
\text { day }\end{array}$ & 219 & 86.9 & 33 & 13.1 & \\
\hline \multicolumn{5}{|c|}{ Leisure time $(\mathrm{n}=388)^{*}$} & \multirow{4}{*}{$\begin{array}{l}x^{2}=0.851 \\
p=0.654\end{array}$} \\
\hline $\begin{array}{l}<2 \text { hours } \\
\text { per week }\end{array}$ & 172 & 84.3 & 32 & 15.7 & \\
\hline $\begin{array}{l}4 \text { to } 7 \text { hours } \\
\text { per week }\end{array}$ & 110 & 82.7 & 23 & 17.3 & \\
\hline $\begin{array}{l}>7 \text { hours } \\
\text { per week }\end{array}$ & 45 & 88.2 & 6 & 11.8 & \\
\hline \multicolumn{5}{|c|}{ Feeling Homesick $(\mathrm{n}=185)^{*}$} & \multirow{3}{*}{$\begin{array}{l}x^{2}=0.692 \\
p=0.406\end{array}$} \\
\hline Yes & 39 & 85.4 & 41 & 14.6 & \\
\hline No & 86 & 81.9 & 19 & 18.1 & \\
\hline \multicolumn{5}{|c|}{ Dietary Changes $(n=455)$} & \multirow{3}{*}{$\mathrm{p}=0.027^{*}$} \\
\hline Yes & 327 & 85.4 & 56 & 14.6 & \\
\hline No & 46 & 74.2 & 16 & 25.8 & \\
\hline
\end{tabular}

*n was substantially lower than 455 because the questions were only applicable to a select number of students 
We assessed the coping strategies adopted by students with burnout (Table 4). Common active strategies were trying to be more positive $(88.1 \%)$ and getting advice $(75.6 \%)$. Of the avoidant coping strategies, positive avoidant strategies such as listening to music (77\%), finding comfort in religious activities (77.4\%) and getting emotional support $(77.9 \%)$ were more commonly used. Roughly half of the burnout affected students coped by keeping their feelings to themselves and trying to deal with the problem on their own $(54.5 \%)$, while a minority of the students indulged in smoking tobacco $(7.3 \%)$, alcohol consumption $(8.7 \%)$ and drug use $(7.6 \%)$.

Table 4. Coping strategies adopted by medical students with burnout syndrome $(n=381)$

\begin{tabular}{|l|l|l|}
\hline & $\mathrm{n}$ & $\%$ \\
\hline $\begin{array}{l}\text { Look for something good in the sit- } \\
\text { uation and try to make it seem more } \\
\text { positive }\end{array}$ & 325 & 85 \\
\hline $\begin{array}{l}\text { I try to get advice from relevant people } \\
\text { and worked accordingly }\end{array}$ & 279 & 75.6 \\
\hline $\begin{array}{l}\text { I try to find comfort in my religion and } \\
\text { spiritual beliefs }\end{array}$ & 285 & 77.4 \\
\hline $\begin{array}{l}\text { I try to reduce stress by listening to } \\
\text { music }\end{array}$ & 284 & 77.0 \\
\hline $\begin{array}{l}\text { I try to get emotional support and com- } \\
\text { fort from friends or colleagues }\end{array}$ & 283 & 77.9 \\
\hline $\begin{array}{l}\text { I keep all my feelings to myself and try } \\
\text { to deal with the problem by myself }\end{array}$ & 200 & 54.5 \\
\hline I smoke tobacco when I am stressed & 27 & 7.3 \\
\hline I consume alcohol when I am stressed & 32 & 8.7 \\
\hline $\begin{array}{l}\text { I use drugs (marijuana, heroin, co- } \\
\text { caine, etc.) when I am stressed }\end{array}$ & 28 & 7.6 \\
\hline
\end{tabular}

\section{Discussion}

The study findings indicate that $83.7 \%$ of 455 Jaffna medical students had BOS, which is substantially higher than the prevalence rates reported from India (52\%)and China (40\%) and much higher than in Brazil $(10 \%)(3,4,12)$. The high prevalence of BOS among medical students at the University of Jaffna is of concern as it is known to be associated with dissatisfaction and intention to drop out(5). Moreover, there are potential implications for patient care, as burnout may continue into professional life, and compromise patient care (2).
We found a significant association between year of study and burnout; $90.2 \%$ of second year students had burnout, followed by fourth $(84.9 \%)$, first $(82 \%)$ and third $(76 \%)$ year students $(\mathrm{p}=0.048)$. By contrast, studies carried out in China show that senior (third and fourth year) medical students are more likely to have burnout(4). Our result may be due to the fact that, at the time of data collection, second year students were approaching their First Examination for Medical Degrees, while third year students did not have upcoming exams.

Although a greater proportion of female students had burnout, there was no evidence of an association between gender and burnout among Jaffna students. These findings are consistent with studies carried out in certain medical schools in China where sex differences in BOS were not identified. However, other studies in the meta-analysis gave contrasting results, indicating that either male or female students were more likely to have BOS (4).

Similarly, ethnicity was not statistically significant although Sinhala students had the highest proportion (88.5\%) of burnout, followed by Sri Lankan Tamils (83.2\%), Muslims (76.6\%) and Indian Tamils (71.4\%). Among students who experienced language difficulties $(n=202), 104$ had difficulties with English, 60 with Tamil, or 38 with both. This means $31 \%(n=142)$ of the sample experienced difficulties with English, a likely stressor as the medium of instruction of the medical course is English.

The results of the First Examination for Medical Degrees had a significant association with burnout $(p=0.019)$. Indeed, all students who had 'missed their batch' had BOS. As a cross-sectional study does not permit arriving at a conclusion on directionality, BOS could be a result of poor exam performance. On the other hand, exam results may have been influenced by BOS and weak coping skills. Regardless, this results suggests that students who 'missed their batch' require additional support as they move through the MBBS programme.

Interaction with lecturers was significantly associated with burnout where medical students who rarely interacted with lecturers were more likely to have burnout $(86.1 \%)$ compared to students who frequently interacted with their lecturers $(74 \%)(p=0.009)$. These findings are consistent with a study of Chinese medical students 
that demonstrated interpersonal relationships and a positive learning atmosphere were negatively associated with certain elements of BOS (4).

Time spent on leisure activities had no significant association with burnout. By contrast, in a study of medical students from Brazil, researchers found that key symptoms of burnout were associated with lack of leisure time. In the same study, high levels of professional efficacy were associated with adequate leisure time (5). The majority of participants $(52.5 \%)$ in the present study spent less than 2 hours a week on leisure activities, which may explain why a significant association was not found.

A significant association was found between social media use and burnout where students who used social media for more than 2 hours were more likely to have burnout $(p=0.021)$. Studies reveal that adolescents who use social media for extended periods and those who are more emotionally invested in social media experience poorer sleep quality, lower self-esteem and higher levels of anxiety and depression (13).

We observed a significant association between change in diet after starting undergraduate studies and burnout ( $\mathrm{p}=0.027$ ). The majority of students reported having changed their $\operatorname{diet}(85.4 \%)$ since entering university and, among them, $85.4 \%$ had burnout. Of the dietary changes, $86.6 \%$ reported having missed meals, $85.5 \%$ eating more fast-food, and $85.1 \%$ reducing intake of fruit and vegetables. Notably, a Malaysian study of medical students demonstrated that $30 \%$ of students deemed dietary changes a source of stress(14).

Jaffna medical students used both active and avoidant coping strategies in dealing with BOS with the majority using active coping strategies. However, the proportion of students using avoidant coping strategies - an independent risk factor for adverse responses to stressful life events (15) was also substantial. The development of positive coping strategies, including personal engagement, extracurricular activities, positive reinterpretation, expression of emotion, studentled mentorship programmes, evaluation systems, career counseling and life coaching, could be useful for students to manage burnout during the MBBS programme (16).
As with any study, this study has several limitations. Although internationally validated, the Oldenburg Burnout Inventory (Student version) has not been validated in Sri Lanka. The questionnaire was administered in English, which is not the first language of most students. As the study was confined to medical students of the University of Jaffna, the generalizability of the findings is limited. However, since all state medical faculties follow the curriculum stipulated by the Sri Lanka Medical Council, further studies on burnout among medical students in other parts of Sri Lanka are needed. Finally, we did not control for confounders when measuring associations.

\section{Conclusion}

Majority $(83.7 \%)$ of first to fourth year medical students of Jaffna University have BOS, indicating the need for urgent measures to address the problem. We recommend the implementation of a mentorship programme that connects incoming students with their lecturers and seniors. While Jaffna medical students use a combination of active and avoidant coping strategies, active coping skills could be further developed and strengthened, possibly through the Personal and Professional Development Stream (PPDS) for medical students.

\section{Acknowledgement}

We thank Dr. B. Kumarendran, Senior Lecturer, Department of Community and Family Medicine, Faculty of Medicine, University of Jaffna, for advice on analysis.

\section{References}

1. Burn-out an "occupational phenomenon"ICD 11 [Internet]. Burn-out an "occupational phenomenon": International Classification of Diseases. 2019. Available from: https://www.who. int/mental_health/evidence/burn-out/en/

2. Shanafelt TD, Balch CM, Bechamps G, Russell T, Dyrbye L, Satele D, et al. Burnout and Medical Errors Among American Surgeons. Ann Surg [Internet]. 2010 Jun [cited 2018 Jul 24];251(6):9951000. Available from: http://www.ncbi.nlm.nih. gov/pubmed/19934755

3. Bera T. Burn Out Among Medical Students - A Study Across Three Medical Colleges in Eastern India. Psicol Reflexão e Crítica [Internet]. 
2013;596(September):356-9. Available from: http://www.scielo.br/scielo.php?script=sci arttext\&pid $=$ S0102-79722012000400010

4. Chunming WM, Harrison R, MacIntyre R, Travaglia $\mathrm{J}$, Balasooriya C. Burnout in medical students: a systematic review of experiences in Chinese medical schools. BMC Med Educ [Internet]. 2017 Dec 16 [cited 2018 Jul 24];17(1):217. Available from: https://bmcmededuc.biomedcentral.com/ articles/10.1186/s12909-017-1064-3

5. Costa EF de O, Santos SA, Santos ATR de A, Melo EV de, Andrade TM de. Burnout Syndrome and associated factors among medical students: a crosssectional study. Clinics (Sao Paulo) [Internet]. 2012 [cited 2018 Jul 24];67(6):573-80. Available from: http://www.ncbi.nlm.nih.gov/pubmed/22760894

6. Supe AN. A study of stress in medical students at Seth G.S. Medical College. J Postgrad Med [Internet]. 1998 [cited 2018 Jul 24];44(1):1-6. Available from: http://www.ncbi.nlm.nih.gov/ pubmed/10703558

7. Kathriarachchi M, Rowntree G. A pilot study on burnout syndrome: its existence, causes and coping strategies practiced by medical professionals in Colombo South Teaching Hospital, Sri Lanka. Sri Lankan J Hum Resour Manag [Internet]. 2016 Dec 1 [cited 2018 Jul 24];6(1):13. Available from: https://sljhrm.sljol.info/article/10.4038/sljhrm. v6i1.5630/

8. Lazarus RS, Folkman S. Stress, Appraisal, and Coping. New York. 1984.

9. Bond FW, Bunce D. Mediators of change in emotion-focused and problem-focused worksite stress management interventions. J Occup Health Psychol. 2000;

10. Dr Prof Daya Somasundara, Somasundaram PD, Mr. Ajmal Imthiyas, Mr.T.Renushant. Influence of academic factors and socio demographic factors in the level of psychological stress among medical of the faculty of medicine, universirtyof jaffna. 2015;

11. Demerouti E, Bakker AB. The Oldenburg Burnout Inventory: A good alternative to measure burnout and engagement. Handb Stress Burn Healthc. 2007;

12. Almeida G de C, Souza HR de, Almeida PC de, Almeida B de C, Almeida GH. The prevalence of burnout syndrome in medical students. Rev Psiquiatr Clin. 2016;

13. Woods HC, Scott H. \#Sleepyteens: Social media use in adolescence is associated with poor sleep quality, anxiety, depression and low self-esteem. J Adolesc. 2016;

14. Al-Dubai SAR, Al-Naggar RA, Alshagga MA, Rampal KG. Stress and Coping Strategies of Students in a Medical Faculty in Malaysia. Malays J Med Sci [Internet]. 2011;18(3):57. Available from: http://www.ncbi.nlm.nih.gov/pubmed/22135602

15. Holahan CJ, Moos RH. Risk, Resistance, and Psychological Distress: A Longitudinal Analysis With Adults and Children. J Abnorm Psychol. 1987;

16. Fares J, Al Tabosh H, Saadeddin Z, El Mouhayyar C, Aridi H. Stress, burnout and coping strategies in preclinical medical students. North American Journal of Medical Sciences. 2016. 